\title{
Inpatient care: should the general physician now take charge?
}

\author{
Varo Kirthi, R Mark Temple and Linda J Patterson
}

\begin{abstract}
In an ageing population, patients are living longer with one or more chronic disease, and with acute illnesses increasingly extending outside the boundaries of a single medical specialty. Therefore, is it time for the general physician to take charge?
\end{abstract}

KEY WORDS: generalism, secondary care, general physician, older people

\section{Introduction}

The National Health Service (NHS) is under unprecedented pressure to meet an ever-increasing demand for healthcare. An important influence is the ageing population, with individuals now living longer with one or more chronic condition. ${ }^{1,2}$ The rising burden of chronic disease means that patients presenting to hospital with an acute illness increasingly have needs that fall beyond the remit of a single system specialty. Despite this, postgraduate medical training, with its focus on specialism, has remained largely unchanged. One notable exception has been the emergence of the field of acute medicine, which has many parallels with the development of hospital-based generalist physicians, or 'hospitalists', in the USA. ${ }^{3}$

In the UK, geriatricians and physicians practising general internal medicine can lay claim to generalist credentials. In this paper, we seek to contribute to the discussion of how the organisation of care in hospital and, specifically, the structure and skills of its medical workforce, can best meet the needs of a population that is becoming older and frailer, with a greater encumbrance of comorbid diseases.

Varo Kirthi, clinical fellow to the president; $\mathbf{R}$ Mark Temple, acute care fellow; Linda J Patterson, OBE, clinical vice president

Royal College of Physicians, London, UK

\section{Evolving requirements for inpatient care}

Since the inception of the NHS in 1948, life expectancy has increased by $18 \%$ to 78.4 years for males and by $16.7 \%$ to 82.4 years for females. ${ }^{4}$ An estimated 15 million people in England now have a long-term condition, accounting for $64 \%$ of all outpatient appointments and $77 \%$ of all hospital admissions. ${ }^{1}$ Approximately half of those aged over 60 have a chronic illness and this will increase over the next 20 years, with the population of those aged over 85 set to double. ${ }^{2}$

Meanwhile, the provision of acute-care services continues to be tested by a relentless increase in the number of attendances in emergency departments and unscheduled hospital admissions. Despite the restructuring of urgent care services and alternatives to admission, emergency attendances in England increased by 46\% between 2003-2004 and 2009-2010, and emergency admissions by $11.8 \%$ in the four years to $2008-2009.5$

One of the most striking changes is that the acute medical take has increasingly become a service for older patients. This patient cohort accounts for a growing proportion of NHS hospital activity every year. In the decade up to 2009-2010, all in-hospital stays in England involving patients aged 75 and over increased by $66 \%$, compared with the overall growth rate of $38 \%{ }^{6}$ Similarly, the number of hospital stays involving 60- to 74-yearolds increased rapidly, by nearly 50\%. ${ }^{6}$ In 2010-2011, the mean length of stay was 6.7 days for all hospital inpatients aged 60-74 and 10.5 days for those aged 75 or over, compared with an overall average of 5.5 days. $^{7}$

In the 2010 Commonwealth Fund appraisal of healthcare services across seven countries, the NHS ranked seventh for patient-centred care. ${ }^{8}$ Evidence that older patients in particular might receive poor levels of care on hospital wards was strikingly highlighted in the Francis Inquiry into the Mid-Staffordshire Hospital and recent Care Quality Commission (CQC) reports. ${ }^{9,10}$ The complex needs of such patients might be neglected, fuelled 
by an over-riding misperception by hospital staff at all levels that the patient is in the 'wrong place. ${ }^{11}$ Failure to provide sensitive care that promotes dignity can have significant negative clinical outcomes. ${ }^{12}$ Furthermore, the high prevalence of dementia, estimated to be approximately $25 \%$ among hospital inpatients, poses particular challenges for clinical management and successful discharge-planning in patients who might not be able to participate fully in decisions about their care. ${ }^{13}$

Two established cohorts of hospital-based generalists pre-date the arrival of acute physicians in NHS hospitals: physicians contributing to general internal medicine (GIM) services in addition to their subspecialty, and geriatricians (ie generalists specialising in the care of older people). Geriatricians now comprise the largest specialty cohort of consultant physicians in the UK, with 1,201 consultants identified in the 2010 census. ${ }^{14}$ However, the growing number of older inpatients throughout hospital wards means that they are commonly not under the care of a geriatrician, even when their admission is complicated by dementia, delirium or frailty. Existing geriatric services, as currently organised, are unlikely to be able to provide continuing medical care for all of these patients.

It is not just the profile of patients on medical wards that has changed: the pattern of older, more dependent patients with multiple comorbid diseases is now seen throughout secondary care services. Although early specialist triage is associated with better outcomes in patients with specific acute illnesses, the evidence is less convincing in the older population. ${ }^{15}$ Older patients admitted with a well-defined acute condition, such as a fractured neck of femur, are at much greater risk of medical deterioration owing to frailty, reduced physiological reserve and multiple comorbidities. General practitioners report concerns about patients being discharged back to the community without having their comorbid issues addressed, resulting, in many cases, in multiple readmissions. ${ }^{16}$ Physicians also have longstanding concerns about the lack of continuity of care, compromising the quality of care delivered, and both patients and staff have highlighted risks resulting from frequent changes of ward and medical teams. In a recent survey by the Royal College of Physicians (RCP), lack of continuity of care for medical inpatients was highlighted as the principal concern by physicians. ${ }^{17} \mathrm{~A}$ recent report by the King's Fund also highlighted the lack of continuity of care for older patients in hospital. ${ }^{18}$

\section{The general internal medicine physician: undervalued and overworked?}

Should generalist physicians have a greater role in the delivery of care to older patients, who now account for the longest lengths of stay throughout the hospital? The development of acute medicine units (AMUs), led by acute physicians, has embedded a generalist approach to patients early in their acute admission and has been associated with reduced mortality and duration of hospital stay. ${ }^{19}$ Specialty triage in AMU should select frail older patients with complex multisystem disease for transfer to older people's wards. However, in reality, many patients will be allocated to the first available bed, often resulting in admission to a medical ward in a subspecialty that is loosely aligned to their major illness.

Although many subspecialty physicians remain dedicated to general internal medicine (GIM) and the acute medical take, GIM practice remains unappealing to many consultants and trainees. The proportion of consultant physicians from the six largest medical subspecialties who maintain a commitment to the acute medical take declined from $76.1 \%$ in 2002 to $60.5 \%$ in $2010 .^{14}$

Currently, $54.5 \%$ of medical registrars in the UK are training towards a dual accreditation in GIM and a subspecialty, but less than half of these (42\%) wish to participate in the acute take on becoming a consultant. ${ }^{20}$ With respect to their medical subspecialty, $88 \%$ of registrars in training report that they were either satisfied or very satisfied with their job, but this fell to $49 \%$ with respect to GIM. ${ }^{20}$ GIM trainees cite the increasing workload and cover for sickness absence, the impact of the European Working Time Directive and inflexible training posts as their principal training concerns. ${ }^{20,21}$ The workload of the on-call medical registrar is also viewed by more junior trainees as particularly arduous, with $80 \%$ reporting this to be 'unmanageable' or 'very unmanageable' (Dillon A et al personal communication). ${ }^{22}$

Consultant GIM duties have been reported to be unpopular because of increasing service requirements, particularly out of hours. Additional reasons are likely to include the workload volume and its unselected nature, lack of specialist prestige, and the extent of medical knowledge and diagnostic skills required to practice GIM to a high standard. GIM ward teams are also at risk of disproportionate depletion of junior medical staff because of on-call duties and restricted junior doctors' hours, compared with medical subspecialties. Specialist registrars training for dual accreditation in GIM and a medical subspecialty might have their only exposure to GIM when taking part in the acute intake, with little responsibility for the ongoing care of general medical patients on the ward.

\section{Reinvigorating GIM}

Although the appeal of generalist practice is declining in the UK, this is in marked contrast to the USA, where the hospital-based general physician, the hospitalist, is in ascendance. Hospitalists have formed the fastest-growing specialty in US history, expanding from a few hundred to 30,000 in just 15 years, with hospitalists now present in approximately $70 \%$ of US hospitals. ${ }^{22}$ In the UK, over a similar timeframe, acute medicine has emerged to become the fastest-growing specialty in the NHS. ${ }^{23}$ Hospitalists in the USA and acute physicians in the UK have many duties and patterns of working in common. However, a key difference is that the hospitalist serves as the responsible physician for patients throughout their hospital stay, whereas acute physicians are responsible for care on the AMU for the first 48-72 hours of hospitalisation. ${ }^{3}$ Furthermore, hospitalists deliver care to patients requiring their expertise irrespective of their location in hospital, often following patients into the intensive care unit and co-managing surgical patients. 
Could this model of continuous care throughout hospitalisation, irrespective of ward location, by a physician with the right skills, be the key to optimising the care of the frail older patient? Translating this model to the UK poses the question of which generalist is best placed to meet this challenge. Geriatricians have the right skill set to routinely manage selected patients on the AMU and oversee their transfer to wards staffed and structured to meet their needs. Geriatricians have also pioneered co-management of surgical patients on orthopaedic wards through the development of orthogeriatric medicine and this approach could be extended to other surgical subspecialties (eg urology and vascular) where older patients particularly predominate. Alternatively, extending the role of acute physicians beyond AMU might export to other hospital wards the improvements in mortality and length of stay associated with care on the AMU. ${ }^{3}$ Finally, meeting headon the changing demography of inpatients with a hospitalisttype model could mean a renaissance for the largest cohort of generalists in the NHS: the GIM physician. The current cap on NHS funding would favour the last option, as a sufficient expansion in the number of geriatric or acute medicine consultants to meet the care requirements of all patients not triaged to a medical subspecialty is unlikely. GIM physicians are already heavily committed to the delivery of continuous on-site care, seven days a week. Reinvigorating GIM from its current lowly status will require the radical re-skilling and restructuring of GIM teams. ${ }^{24}$

Most patients admitted as a medical emergency in the UK might benefit from continuing care by a generalist with subspecialists adopting primarily a consulting and intervention role. As a result, subspecialist teams would reduce the number of inpatients for whom they have ongoing care (specifically relinquishing their complex older patients) and release bed capacity and their more junior trainees to generalist teams. This redeployment of trainees, coupled with a renewed emphasis on the acquisition of skills required to meet the needs of older patients, would, if applied in GIM, help rebalance the workload, enhance training and re-enthuse trainees and consultants. This enhanced trainee staffing would reduce the risk of fracturing team- and wardbased continuous care, from conflicting on-call duties. In short, there is a strong case for inpatients whose acute illness extends beyond the confines of a single system specialty to have a much greater opportunity to be cared for by a stable generalist team, structured to ensure continuity of care and a frequency of senior clinical review that meets their needs.

There is an emerging body of research that shows that general medical care delivered by hospitalists in the USA has reduced length of hospital stay and costs, but the impact on quality of care is variable. ${ }^{3}$ However, the evidence to guide best practice in relation to the delivery of acute care, particularly in the frail, older patient, is extremely limited. Therefore, there is a crucial requirement to promote research and evaluate services to determine which elements of the organisation of care have the greatest impact on patient outcomes. The RCP has recently launched a commission on the 'future hospital', aiming to 'identify the optimal care pathway for adult inpatients with medical illness, with specific reference to organisation, processes and standards of care. This commission is due to report in Spring 2013.

\section{Conclusion}

The past two decades have seen a revolution in how acute care has been organised on AMUs, by a new class of physicians with skills tailored to meet the requirements of newly hospitalised patients. The changing profile of hospital inpatients necessitates health services that formerly championed the delivery of increasingly specialised medicine to now evolve to meet the care needs of older patients who fail to neatly align with a single system specialty. The challenge for the next decade is how to organise medical care of the highest quality for inpatients on medical and surgical wards other than AMU, and to determine the expertise, skills and working patterns of the physicians who should deliver this care.

\section{Competing interest}

All three authors have recently written an editorial for the BMJ entitled 'The evolving requirements for inpatient care - time for a new physician model?' which was accepted for publication on 20 March 2012. All three authors are also involved in the RCP commission on the future hospital.

\section{References}

1 Department of Health, 2011. GP patient survey Jan-Dec 2011, scaled to General Lifestyle Survey 2009. www.dh.gov.uk/en/MediaCentre/ Pressreleases/DH_128890 [Accessed 28 May 2012].

2 Dilnot A, Warner N, Williams J. Fairer care funding. Commission on Funding of Care and Support. London: DH 2011.

3 Wachter RM, Bell D. Renaissance of hospital generalists. BMJ 2012;344:e652.

4 Department of Health. Mortality Monitoring Bulletin (life expectancy and all-age-all-cause mortality, and mortality from selected causes, overall and inequalities): update to include data for 2010. London: DH, 2011. www.dh.gov.uk/en/Publicationsandstatistics/Publications/ PublicationsStatistics/DH_130282 [Accessed 28 May 2012].

5 Blunt I, Bardsley M, Dixon J. Trends in emergency admissions in England 2004-2009: is greater efficiency breeding inefficiency? London: The Nuffield Trust, 2010.

6 NHS Information Centre. Hospital episode statistics HES (admitted patient care) England 2009/10. London: NHS Information Centre, 2010. www.ic.nhs.uk/pubs/hes0910 [Accessed 28 May 2012].

7 NHS Information Centre. HES online: Headline figures 2010-11. London: NHS Information Centre, 2011. www.hesonline.nhs.uk/Ease/ servlet/ContentServer?siteID=1937\&categoryID=193 [Accessed 28 May 2012].

8 Davis K, Schoen C, Stremikis K. Mirror, mirror on the wall: how the performance of the U.S. health care system compares internationally, 2010 update. New York: the Commonwealth Fund, 2010.

9 Department of Health. Robert Francis Inquiry report into MidStaffordshire NHS Foundation Trust. London: DH, 2010. www.dh.gov. uk/en/Publicationsandstatistics/Publications/Publications PolicyAndGuidance/DH_113018. [Accessed 28 May 2012].

10 Care Quality Commission. Dignity and nutrition inspection programme: national overview. London: CQC, 2011. www.cqc.org.uk/sites/ 
default/files/media/documents/20111007_dignity_and_nutrition_ inspection_report_final_update.pdf [Accessed 28 May 2012].

11 Tadd W, Hillman A, Calnan S et al. Dignity in practice: an exploration of the care of older adults in acute NHS trusts. London: Her Majesty's Stationery Office, 2011.

12 Beach MC, Sugarman J, Johnson RL et al. Do patients treated with dignity report higher satisfaction, adherence, and receipt of preventive care? Ann Fam Med 2005;3:331-8.

13 The Alzheimer's Society. Counting the cost: caring for people with dementia on hospital wards. London: Alzheimer's Society, 2009.

14 Goddard A. Census of consultant physicians and medical registrars in the UK (2010). London: Royal College of Physicians, 2011.

15 Moore S, Gemmell I, Almond S et al. Impact of specialist care on clinical outcomes for medical emergencies. Clin Med 2006;6:286-93.

16 RCGP Commission on Generalism. Guiding patients through complexity: modern medical generalism. London: RCGP, 2011. www.rcgp. org.uk/policy/commissn_on_generalsm.aspx [Accessed 28 May 2012].

17 RCP membership engagement survey, 2012. www.rcplondon.ac.uk/ commentary/membership-engagement-survey-results-2012 [Accessed 10 July 2012].

18 Cornwell J, Sonola L, Levenson R, Poteliakhoff E. Continuity of care for older hospital patients: a call for action. London: The King's Fund, 2012.
19 Byrne D, Silke B. Acute medical units: review of evidence. Eur J Intern Med 2011;22:344-7.

20 Goddard A, Evans T, Phillips C. Medical registrars in 2010: experience and expectation of the future consultant physicians of the UK. Clin Med 2011;11:532-5.

21 NHS Information Centre. Sickness absence rates in the NHS: April-June 2009. London: NHS Information Centre, 2009. www.ic.nhs.uk/webfiles/publications/absenceratesjune09/sickness_absence_april_ june_\%202009.pdf [Accessed 28 May 2012].

22 Wachter RM. The hospitalist field turns 15: new opportunities and challenges. J Hosp Med 2011;6:E1-4.

23 Ward D, Potter J, Ingham J et al. Acute medical care. The right person, in the right setting--first time: how does practice match the report recommendations? Clin Med 2009;9:553-6.

24 Ellis G, Whitehead MA, O'Neill D et al. Comprehensive geriatric assessment for older adults admitted to hospital. Cochrane Database Syst Rev 2011;7:CD006211.

Address for correspondence: Dr LJ Patterson, The Royal College of Physicians, 11 St Andrew Place, Regent's Park, London, NW1 4LE.

E-mail: linda.patterson@rcplondon.ac.uk

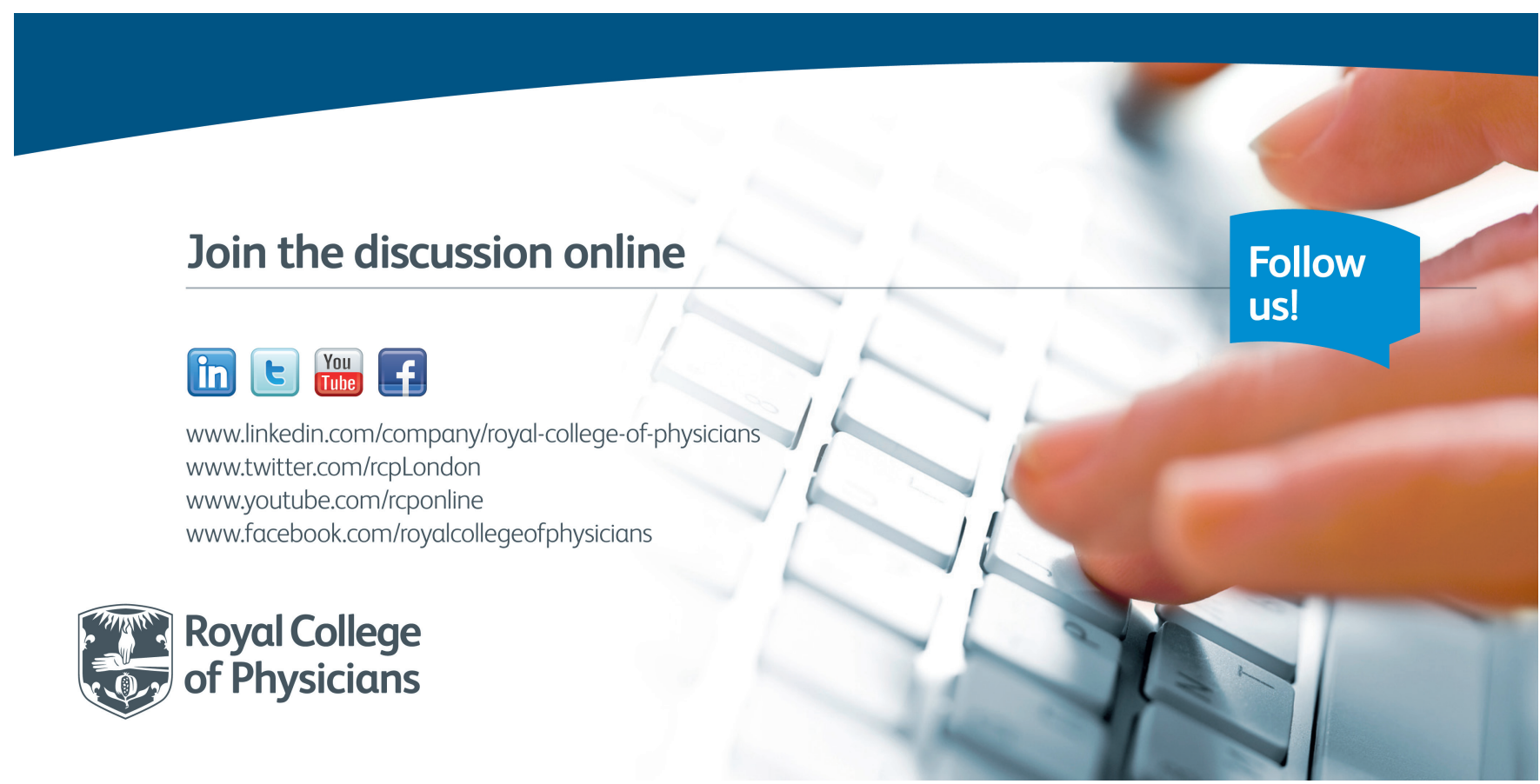

